\title{
Screening for Ovarian Cancer by Different Modes of Transvaginal Sonography
}

\author{
${ }^{1}$ Asim Kurjak, ${ }^{2}$ Matija Prka
}

\begin{abstract}
Studies indicate that 3D power Doppler imaging can improve the ability to differentiate benign from malignant ovarian masses, increasing significantly specificity and positive predictive value (PPV) in ovarian cancer detection. Therefore, the problem of low PPV in ultrasound-only strategies may be solved by introducing new 3D ultrasound technologies, used together in a secondary screening procedure. The possible role of 3D ultrasound and 3D power Doppler imaging in the early and accurate detection of ovarian cancer is under evaluation through Zagreb Ovarian Cancer Screening Trial.
\end{abstract}

Keywords: 3D power Doppler, Early detection, Malignant ovarian masses, Screening

How to cite this article: KurjakA, Prka M. Screening for Ovarian Cancer by Different Modes of Transvaginal Sonography. Donald School J Ultrasound Obstet Gynecol 2018;12(3):186-196.

Source of support: Nil

Conflict of interest: None

\section{INTRODUCTION}

In developed countries, more women die annual ly from ovarian cancer than from all other gynecologic malignancies combined. For example, in the United States, approximately 25,580 new cases are diagnosed each year, and 16,090 of these women will die of the disease. ${ }^{1}$ Symptoms usually do not become apparent until the tumor compresses or invades adjacent structures, ascites develops, or metastases becomes clinically evident. As a result, around $65 \%$ of women with ovarian cancer have advanced disease (Stage III/IV) at diagnosis with a 5-year survival rate of only 20 to $30 \%$, compared with the 5 -year survival of over $90 \%$ in patients with stage IA ovarian cancer, when the disease is confined to the ovary. ${ }^{2}$ Given the burden of suffering associated with the development of ovarian cancer and the clear survival gradient related to the stage of disease at diagnosis, ${ }^{3}$ there is much enthusiasm for the development of effective screening methods / assays for the early detection of epithelial ovarian cancer.

\footnotetext{
${ }^{1}$ Professor Emeritus, ${ }^{2}$ Specialist

1,2Department of Obstetrics and Gynecology, Medical School University of Zagreb, Sveti Duh Hospital, Zagreb, Croatia

Corresponding Author: Asim Kurjak, Professor Emeritus, Department of Obstetrics and Gynecology, Medical School University of Zagreb, Sveti Duh Hospital, Zagreb, Croatia, e-mail: asim.kurjak@public.srce.hr
}

\section{DIFFICULTIES IN OVARIAN CANCER SCREENING}

The ability to detect early-stage epithelial ovarian cancer by a simple test has long been desired yet never achieved. Several aspects of ovarian cancer have led to the frustrations that have been encountered in attempts to screen for the disease. ${ }^{4}$ First, the anatomic location of the ovaries is not amenable to any direct inspection. Additionally, in contrast to cervical neoplasia, epithelial ovarian cancers lack any defined precursor lesion and have a poorly defined natural history. The time required for the localized disease to progress to disseminated disease is unclear; therefore the appropriate interval at which to pursue screening is at this point chosen arbitrarily. Other impediments to screening relate to the low prevalence of ovarian cancer in the general population. Therefore, a specificity of $99.6 \%$ is required to achieve a positive predictive value of $10 \%$, i.e., to limit the number of unnecessary surgical procedures to 10 for each case of cancer detected. ${ }^{5}$ A specificity lower than this is likely to be unacceptable in this population, although may be acceptable to those with a positive family history of breast or ovarian cancer.

\section{ATTEMPTS TO SCREEN SOME LESSONS LEARNED}

During the last decade, large prospective studies of screening for ovarian cancer have been performed. ${ }^{6}$ Two distinct strategies have emerged, one based on ultrasound as the primary test, and the other involving the serum tumor marker CA 125 for primary screening with ultrasound as the secondary test (multimodal screening). Tables 1 and 2 summarize the prospective ovarian cancer screening studies in the general population. ${ }^{7-22}$ If we exclude those which used transabdominal ultrasound, an abandoned screening strategy due to the unacceptably high rate of false-positive results, several important lessons can be learned for forthcoming trials.

As seen in Tables 1 and 2, the data suggest that sequential multimodal screening has greater specificity and positive predictive value compared to strategies based on transvaginal ultrasound alone. For each case of ovarian cancer detected, five women underwent surgery in the multimodal studies compared to 24 women in the studies using ultrasound alone. However, transvaginal 
Table 1: Prospective ovarian cancer screening studies using ultrasound as the primary test in the general population

\begin{tabular}{|c|c|c|c|c|c|c|}
\hline Study & $\begin{array}{l}\text { Inclusion } \\
\text { criteria }\end{array}$ & $\begin{array}{l}\text { Screening } \\
\text { strategy }\end{array}$ & No. of screened & $\begin{array}{l}\text { No. of invsive } \\
\text { epithelial ovarian } \\
\text { cancers detected }^{a}\end{array}$ & $\begin{array}{l}\text { No. of } \\
\text { positives } \\
\text { screens } \\
\end{array}$ & $\begin{array}{l}\text { No. of } \\
\text { positive } \\
\text { screens/ } \\
\text { cancer } \\
\text { detected }^{b}\end{array}$ \\
\hline \multicolumn{7}{|c|}{ Ultrasound (US) approach } \\
\hline \multicolumn{7}{|c|}{ Grayscale US (Level 1 screen), than repeat grayscale US (Level 2 Screen) } \\
\hline Nagell et al. ${ }^{7}$ & $\begin{array}{l}\text { Age }>50 \text { years } \\
\text { and postmeno- } \\
\text { pausal or }>30 \text { with } \\
\text { positive family } \\
\text { history }\end{array}$ & $\begin{array}{l}\text { TVS } \\
\text { Annual } \\
\text { screens } \\
\text { Mean } 4 \\
\text { screens/ } \\
\text { women }\end{array}$ & 14469 & $\begin{array}{l}11(6) \\
5 \text { Stage }\end{array}$ & 180 & 16,4 \\
\hline Hayashi et al. ${ }^{8}$ & Age $>50$ years & TVS & 23451 & $3(3)$ & 258 & c \\
\hline Tabor et al. ${ }^{9}$ & Aged $46-65$ years & TVS & 435 & 0 & 9 & - \\
\hline Campbell et al. ${ }^{10}$ & $\begin{array}{l}\text { Age }>45 \text { years } \\
\text { or with positive } \\
\text { family history }(4 \%)\end{array}$ & $\begin{array}{l}\text { TAS } \\
3 \text { screens at } \\
18 \\
\text { monthly } \\
\text { intervals }\end{array}$ & 5479 & $\begin{array}{l}2(3) \\
2 \text { Stage I }\end{array}$ & 326 & 163 \\
\hline Goswamy et al. ${ }^{11}$ & $\begin{array}{l}\text { Age } 39-78 \\
\text { Postmenopausal }\end{array}$ & TAS & 1084 & $\begin{array}{l}1 \\
1 \text { Stage I }\end{array}$ & $\begin{array}{l}\text { not } \\
\text { precised }\end{array}$ & - \\
\hline \multicolumn{7}{|c|}{ Grayscale US and CDI (Level 1 screen) } \\
\hline Vuento et al. ${ }^{12}$ & Aged $56-61$ years & TVS and CDI & 1364 & $(1)$ & 5 & - \\
\hline Kurjak et al. ${ }^{13}$ & $\begin{array}{l}\text { Aged } 40-71 \text { years } \\
4 \text { stage I }\end{array}$ & TVS and CDI & 5013 & 4 & 38 & 9,5 \\
\hline Schulman et al. ${ }^{14}$ & $\begin{array}{l}\text { Age }>40 \text { years or } \\
>30 \text { with positive } \\
\text { family history }\end{array}$ & TVS and CDI & 2117 & 1 & 18 & 18 \\
\hline \multicolumn{7}{|c|}{ Grayscale US (Level 1 screen) and other tests (Level 2 screen) } \\
\hline Sato et al. ${ }^{15}$ & Age $>30$ years & $\begin{array}{l}\text { TVS then } \\
\text { tumour } \\
\text { markers if } \\
\text { TVS +, } \\
\text { CT and MRI } \\
\text { if all previous } \\
+\end{array}$ & 51550 & $\begin{array}{l}16(6) \\
12 \text { Stage I }\end{array}$ & 324 & 20,3 \\
\hline Parkes et al. ${ }^{16}$ & Aged 50-64 & $\begin{array}{l}\text { TVS then CDI } \\
\text { if TVS + }\end{array}$ & 2953 & $\begin{array}{l}1 \\
1 \text { Stage I }\end{array}$ & 15 & 15 \\
\hline Holbert et al. ${ }^{17}$ & $\begin{array}{l}\text { Postmenopausal } \\
\text { Aged } 30-89 \text { years }\end{array}$ & $\begin{array}{l}\text { TVS then CA } \\
125 \text { if TVS + }\end{array}$ & 478 & $\begin{array}{l}1 \\
1 \text { Stage I }\end{array}$ & $33^{d}$ & - \\
\hline TOTAL $^{\mathrm{e}}$ & & & & $\begin{array}{l}37(16) \\
23 \text { Stage I }\end{array}$ & 880 & 23,8 \\
\hline
\end{tabular}

TAS = Transabdominal ultrasound; TVS = Transvaginal ultrasound; CDI = Color Doppler imaging

${ }^{\text {aT }}$ The borderline/granulosa tumors detected are shown in parenthesis

${ }^{b}$ Only invasive epithelial ovarian cancers included

'Only 95 women consented to surgery and there are no follow-up details on the remaining

${ }^{\mathrm{d} O n l y} 11$ of these women underwent surgery

eStudies used TAS are excluded

ultrasound as a first line test may offer higher sensitivity for early-stage disease given that $23 / 37(62.2 \%)$ cancers detected using ultrasound alone were stage I, compared to $8 / 19$ (42.1\%) cancers detected by the multimodal strategy. An ultrasound-based strategy may have a greater impact on ovarian cancer mortality, albeit at a higher price in terms of surgical intervention for false positive results.

This article updates the status of ovarian cancer screening and addresses most relevant studies published during the last years. The developments that followed the review are best summarized in reference to the screening tests, target populations, and newly published trials. The possible role of 3D ultrasound technology, especially 3D power Doppler imaging in the early and accurate detection of ovarian malignancy is discussed. Finally, we describe our new ovarian cancer screening trial, which started in January 2001.

\section{SCREENING TESTS}

Screening for ovarian cancer has been based on strategies using serum tumor markers or transvaginal ultrasound images of the ovaries. 
Table 2: Prospective ovarian cancer screening studies using serum CA 125 as the primary test in the general population

\begin{tabular}{|c|c|c|c|c|c|c|}
\hline Study & $\begin{array}{l}\text { Inclusion } \\
\text { criteria }\end{array}$ & $\begin{array}{l}\text { Screening } \\
\text { strategy }\end{array}$ & $\begin{array}{l}\text { No. of } \\
\text { screened }\end{array}$ & $\begin{array}{l}\text { No. of invsive } \\
\text { epithelial ovarian } \\
\text { cancers detected }\end{array}$ & $\begin{array}{l}\text { No. of } \\
\text { positives } \\
\text { screens }\end{array}$ & $\begin{array}{l}\text { No. of positive } \\
\text { screens/cancer } \\
\text { detected }\end{array}$ \\
\hline \multicolumn{7}{|l|}{ CA 125 only } \\
\hline Einhorn et al. ${ }^{18}$ & Age $>40$ years & Serum CA 125 & 5550 & $\begin{array}{l}6 \\
2 \text { Stage I }\end{array}$ & 175 & 29.2 \\
\hline \multicolumn{7}{|c|}{ Multimodal Approach } \\
\hline \multicolumn{7}{|c|}{ CA 125 (Level 1 Screen), Then Gray-scale US (Level 2 screen) } \\
\hline Jacobs et al. ${ }^{19}$ & $\begin{array}{l}\text { Age }>45 \text { years } \\
\text { Postmenopausal } \\
3 \text { annual } \\
\text { screens }\end{array}$ & $\begin{array}{l}\text { RCT } \\
\text { Serum CA } 125 \\
\text { TAS/TVS, if CA } \\
125 \uparrow\end{array}$ & 10958 & $\begin{array}{l}6 \\
3 \text { Stage I }\end{array}$ & 29 & 4.8 \\
\hline Jacobs et al. ${ }^{20}$ & $\begin{array}{l}\text { Age }>45 \text { years } \\
\text { Postmenopausal }\end{array}$ & $\begin{array}{l}\text { Serum CA } 125 \\
\text { TAS, if CA } 125 \uparrow\end{array}$ & 22000 & $\begin{array}{l}11 \\
4 \text { Stage I }\end{array}$ & 41 & 3.7 \\
\hline Adonakis et al. ${ }^{21}$ & Age $>45$ years & $\begin{array}{l}\text { Serum CA } 125 \\
\text { TVS, if CA } 125 \uparrow\end{array}$ & 2000 & $\begin{array}{l}1 \text { (1) } \\
1 \text { Stage I }\end{array}$ & 15 & 15 \\
\hline Grover et al. ${ }^{22}$ & $\begin{array}{l}\text { Age }>40 \text { years } \\
\text { or with positive } \\
\text { family history } \\
(3 \%)\end{array}$ & $\begin{array}{l}\text { Serum CA } 125 \\
\text { TAS/TVS, if CA } \\
125 \uparrow \\
3 \text { screens }\end{array}$ & 2550 & 1 & 16 & 16 \\
\hline TOTAL $^{a}$ & & & & $\begin{array}{l}19(1) \\
8 \text { Stage I }\end{array}$ & 101 & 5.3 \\
\hline
\end{tabular}

$\mathrm{RCT}=$ Randomised controlled trial

${ }^{a}$ Only multimodal approach studies included.

\section{Serum Tumor Markers}

In epithelial ovarian cancer, a number of tumor markers have been identified. Serum CA 125 continues to be the tumor marker most extensively used in ovarian cancer screening. ${ }^{23}$ Although CA 125 is elevated $(>35 \mathrm{U} / \mathrm{mL})$ in more than $80 \%$ of patients with epithelial ovarian cancer it is only $25 \%$ sensitive for early stage disease..$^{24}$ Indeed, its value as an initial screening tool is limited since picking up Stage III disease at an earlier time may not alter the outcome. To improve further the performance of CA 125 as a screening tool, an algorithm incorporating age, the rate of change of CA 125 and absolute levels to calculate an individual's risk of ovarian cancer has been described. ${ }^{25}$ This increases the sensitivity of CA 125 in comparison with a single cutoff value because women with normal but rising levels are identified as being at increased risk. This approach is an integral part of the multimodal screening strategy adopted in the St Bartholomew's Hospital newest randomized control trial. ${ }^{26}$

Another limitation of serum CA 125 represents that it is not specific for ovarian carcinoma because it can be elevated in many benign conditions such as endometriosis, uterine fibroids, pelvic inflammatory disease, ascites or pleural effusion. ${ }^{27}$ It is now known that the CA 125 antigen carries two major antigenic domains classified as $\mathrm{A}$ (the domain binding monoclonal antibody OC125) and B (the domain binding monoclonal antibody M11). New generation assays, combining monoclonal antibodies to the two distinct regions of the molecule, have been shown to have improved specificity for the detection of early ovarian cancer. ${ }^{28}$

Lysophosphatidic acid (LPA), a bioactive phospholipid with mitogenic and growth factor-like activities, ${ }^{29}$ is a novel tumor marker that holds promise in ovarian cancer screening. In a small pilot series plasma LPA levels were elevated in 9 out of 10 patients with stage I ovarian cancer, 24 of 24 patients with Stages II, III and IV ovarian cancer, and all 14 patients with recurrent ovarian cancer. ${ }^{30}$ In comparison, among a subset of patients with ovarian cancer, only 28 out of 47 had elevated CA 125 levels, including 2 of 9 patients with Stage I disease. Larger studies on the use of LPA in primary screening-perhaps in combination with other procedures, such as transvaginal ultrasound are essential for earlier detection and improved outcome for patients with ovarian cancer. ${ }^{31}$

\section{Transvaginal Ultrasound}

Transvaginal ultrasound is used in most screening strategies either as the sole screening modality or as a secondary test after the primary screening with serum CA 125 (multimodal screening). As data regarding outcome accumulate with long-term follow up of the participants of the early screening trials, it has been possible to define the further risk of ovarian cancer associated with various ultrasound findings.

Particular results of the largest ultrasound-based ovarian cancer screening project from the University of Kentucky might have a definitive impact on the design 
of future ovarian cancer screening trials in the general population. ${ }^{32}$ Van Nagell et al. established that unilocular ovarian cysts less than $10 \mathrm{~cm}$ in diameter, found in 256 out of $7705(3.3 \%)$ asymptomatic women aged more than 50 years, are associated with minimal risk for ovarian cancer because there were no cases of ovarian carcinoma during a 5-year follow-up period. ${ }^{33}$ In contrast, 7 out of the 250 women in the same study with complex cystic ovarian tumors, including wall abnormalities or solid areas, had ovarian carcinoma suggesting that these morphologic appearances are associated with a significant risk for malignancy.

In many screening algorithms, volume cut-offs are used in addition to morphology characteristics to identify women for intensive surveillance. Recently, based on the data on 58,673 observations of ovarian volume, authors from Kentucky concluded that the upper limit of normal for ovarian volume is $20 \mathrm{~cm}^{3}$ in premenopausal women and $10 \mathrm{~cm}^{3}$ in postmenopausal women. ${ }^{34}$ Such data are invaluable in determining optimal strategies for operative intervention in screening trials.

Postmenopausal women from the general population with an elevated serum CA 125 level but normal ovarian morphology on ultrasound were found to have a cumulative risk of ovarian cancer during a median follow up of 6.8 years, of $0.15 \%$, which was similar to $0.22 \%$ of the entire population of 22,000 women. ${ }^{35}$ In contrast, those with an elevated serum CA 125 level and abnormal ovarian morphology on ultrasound had a significantly increased cumulative risk of $24 \%$. The use of ovarian morphology to interpret pelvic ultrasound may increase sensitivity, and use of complex ovarian morphology may increase the positive predictive value of a multimodal screening strategy. ${ }^{36}$

\section{TARGET POPULATIONS}

Participants for ovarian cancer screening trials are recruited from general and high-risk populations on the basis of risk factors for the disease.

\section{General Population}

\section{Age and Menopausal Status}

The bulk of ovarian cancers occur in the general population, and age greater than 50 years and postmenopausal status have been used to define those eligible for screening. According to the recent FIGO report, ${ }^{2}$ the appeara nce of ovarian cancer is most common among women in early postmenopausal, an average age of 54 years. Law et al. ${ }^{37}$ used national statistics to determine the number of years of life lost through deaths from particular cancer at each age. They concluded that screening would be most effective (i.e., associated with the largest number of years of life saved per person screened) if done 5 years before the loss of life peaked. The peak occur red in ovarian cancer during the age range 55 to 59 years, and the authors' argument provides further justification for using 50 years as the cutoff to commence population screening.

\section{High-risk Population}

\section{Family History and/or Genetic Predisposition}

Approximately 5 to $10 \%$ of ovarian cancers are inherited. Mutations in BRCA1 and BRCA2 genes account for about $75 \%$ of families with a highly penetrant dominantly inherited breast or ovarian cancer family history. Recent estimates of the lifetime risk for ovarian cancer in women harboring a BRCA1 mutation are 40 to $60 \%{ }^{38}$ Various studies have put forward schemes for stratifying women into different risk categories of risk for breast and ovarian cancer by family history, genetic predisposition or both. Pharoah et al. ${ }^{39}$ reviewed the relevance of family history in defining the target population for familial ovarian cancer screening, and propose the adoption of a unified management strategy based on eligibility criteria from UK National Familial Ovarian Cancer Screening Study (Table 3). A survey by Vasen et al. ${ }^{40}$ of the European Familial Breast Cancer Collaborative Group found that the following high-risk populations were offered ovarian cancer screening: BRCA1 and BRCA2 mutation carriers; members of breast/ovarian cancer families; and, in some centres, members of breast cancer only families with an early onset of breast cancer.

\section{OVARIAN CANCER SCREENING TRIALS}

Clinical trials of ovarian cancer screening have involved strategies using ultrasound alone, and a multimodal approach with CA 125 as a primary test and ultrasound as a secondary test. Prospective studies have involved both the general and high-risk populations.

\section{General Population}

\section{Ultrasound Screening}

In the most recent update from the University of Kentucky trial, the results of annual transvaginal ultrasound screening performed on 14,469 asymptomatic women aged 50 years or more and women aged 25 years or more with a family history of ovarian cancer were reported. ${ }^{7}$ 180 patients with persisting transvaginal abnormalities were subjected to surgical intervention. 17 primary ovarian cancers were detected of which 11 were epithelial ovarian cancers (EOC), three were granulosa cell tumors, 
Table 3: Eligibility criteria for the UK National Familial Ovarian Cancer Screening Study ${ }^{39}$

An eligible woman must be over 25 years of age and a first degree relative of an affected member of an "at risk" family. At risk families are defined by the following criteria:

1 Two or more first degree relatives ${ }^{a}$ with ovarian cancer.

2 One first degree relative with ovarian cancer and one first degree relative with breast cancer diagnosed under 50 years of age.

3 One first degree relative with ovarian cancer and two first or second degree relatives ${ }^{\mathrm{b}}$ with breast cancer diagnosed under 60 years of age.

4 An affected individual with one of the known ovarian cancer predisposing genes.

5 Three first degree relatives with colorectal cancer with at least one diagnosed before the age of 50 years and at least one first degree relative with ovarian cancer.

\footnotetext{
${ }^{a} \mathrm{~A}$ first degree female relative is mother, sister or daughter. ${ }^{\mathrm{b}} \mathrm{A}$ second degree female relative is grandmother, granddaughter, aunt or niece.
}

and three were borderline tumors. Of the EOC, 5 were Stage I, 3 were Stage II and 3 were Stage III. In this study transvaginal ultrasound (TV US) as a screening modality was associated with sensitivity of $81 \%$, specificity of $98.9 \%$, the positive predictive value of $9.4 \%$, and negative predictive value of $99.97 \%$ for detection of all primary ovarian cancers. The survival of patients with EOC in the annually screened population was $92.9 \%$ at 2 years and $83.6 \%$ at 5 years. What is encouraging about these results is that annual TV US screening appeared to achieve the primary goal of earlier detection of disease, which translates into a reduction in mortality associated with ovarian carcinoma. On the other hand, data from this study suggested that in certain cases, the length of time required for ovarian cancer to progress from a localized sonographically detectable tumor to widespread regional disease is quite short. In four patients in the false-negative group disease progression from sonographically normal ovaries to Stage II or III, ovarian cancer occurred in less than 12 months. Authors stated that in future screening algorithms, consideration should be given to a screening interval of 6 months.

In the recently published Japanese ovarian cancer screening trial, 51,550 women aged 30 years or more attending for annual cervical screening underwent TV US screening for ovarian cancer. ${ }^{15} 324$ women with masses of more than $60 \mathrm{~mm}$ in diameter or with a mixed-echo pat tern or persistently raised tumor markers underwent laparotomy. Twenty-two primary ovarian tumors and two metastatic tumors were detected. Of the 22 primary tumors, 16 were EOCs, four were borderline malignancies, and two were germ cell tumors. $11(68.7 \%)$ of the EOCs were Stage I, with tumor markers positive in 5 $(45.4 \%)$ of the 11 cases. The positive predictive value of the screening strategy was $4.9 \%$; in other words, 20 operations were undertaken for each detected case of ovarian cancer. As no follow-up data were reported on any of the trial participants, it is difficult to assess the sensitivity of the screening strategy. Before the onset of the screening, the authors note that only $29.7 \%$ of 35 cancers diagnosed in the department were Stage I while after the trial was initiated $58.8 \%$ of 85 ovarian cancers treated were Stage I.

\section{Multimodal Screening}

One of the most active group in screening for ovarian malignancy led by Jacobs recently reported the results of the first completed randomized trial of ovarian cancer screening. ${ }^{19}$ This study randomized asymptomatic postmenopausal women aged 45 years or older to no screening $(\mathrm{n}=10977)$ or annual multimodal screening for 3 years $(\mathrm{n}=10$ 958). In the screening group, 29 women with raised CA 125 values and abnormal ultrasound findings were referred for surgical investigation. All six ovarian cancers detected were EOCs; 3 were Stage I and 3 were Stage III. The authors found a high positive predictive value of $20,7 \%$ with this schema and were encouraged by a longer median survival (72.9 months) in women with ovarian cancer in the screened group when compared to the control group (41, 8 months). The mortality rates, however, were not significantly different between the groups. The authors concluded that the results do not justify ovarian cancer screening in the general population but do support the need for a larger randomized trial that is powered to assess the impact of screening on mortality.

\section{High-risk Population}

For women with a known germline mutation or with a family history suggesting a significant possibility of a genetic predisposition to ovarian cancer, the appropriate screening strategy remains undefined. In recent studies, most authors advocate multimodality screening using TV US and serum CA 125 in patients who elect to delay or decline prophylactic oophorectomy. However, there is no consensus as to the appropriate interval for screening.

Karlan et al. reported the results of an ovarian cancer screening program launched in 1991, involving 1261 women aged over 35 years with a family history of ovarian, breast, colon or endometrial carcinoma, or a personal history of breast cancer. ${ }^{41}$ Screening with TV US, color Doppler imaging and CA 125 was initially performed biannually until 1995, and annually thereafter. Two tumors of low malignant potential, one stage I EOC and 7 cases of primary peritoneal serous papillary carcinoma were diagnosed. Ultrasound abnormalities triggered surgical exploration in all three cases of the 
ovarian disease. In 2 out of 7 cases, elevated levels of CA 125 were the harbinger of peritoneal serous papillary carcinoma, in two abnormal ultrasound findings prompted diagnosis, and three developed interval cancers 5.6 and 16 months after screening. At least three of the patients with primary peritoneal cancer carried mutations of the BRCA1 gene. Multifocal peritoneal serous papillary carcinoma may be a phenotypic variant of familial ovarian cancer, and screening strategies for these women cannot rely on ultrasound and CA 125 testing to detect early disease.

\section{OVARIAN CANCER-ROLE OF 3D ULTRASOUND AND 3D POWER DOPPLER IMAGING}

Improvements in ultrasound technology such as 3D volume acquisition and 3D power Doppler imaging may have clinical utility in the more reliable identification of abnormal ovarian vascularity and architecture. 3D volume acquisition allows for careful evaluation of the internal surfaces of cyst walls for excres cences otherwise not appreciated by 2D ultrasound. ${ }^{42,43}$ While the addition of 3D power Doppler provides a new tool for measuring the quality of ovarian tumor angiogenesis, ${ }^{44}$ improving accurate diagnosis of ovarian malignancies, ${ }^{45}$ its clinical value for the early detection of ovarian carcinoma has yet to be determined.

\section{What does 3D Ultrasound Add?}

In the pioneering work, Bonilla-Musoles et al. ${ }^{42}$ tried to determine whether 3D ultrasound may offer advantages over 2D ultrasound as a screening tool for the evaluation of ovarian lesions. Seventy-six women with ovarian masses first detected with 2D ultrasound were then evaluated with 3D ultrasound. The 3D sonographic criteria used for diagnosing ovarian malignancy were based on the morphologic scoring system for 2D transvaginal ultrasound examinations proposed by different authors. ${ }^{46-49}$ A score greater than 4 caused suspicion of a malignant ovarian mass. ${ }^{49}$ The images were dissected in the three perpendicular planes, and the areas indicative of malignancy, as suggested by 2D ultrasonography, were determined to be either negative or positive and confirmatory. Five lesions observed on 2D ultrasound were suspected to be malignant. 3D sonography identified four of these lesions as malignant. The remaining one suspected to be malignant on 2D ultrasound was diagnosed as endometriosis with 3D sonography. One additional ovarian carcinoma was diagnosed by 3D scanning. Two of the malignant lesions were FIGO stage IA. The other tumors were FIGO Stages IC, IIC, and IIIB, respectively. Authors stated that observation of papillary projections (especially those less than $3 \mathrm{~mm}$ ), characteristics of cystic walls, and the extent of capsular infiltration was superior with $3 \mathrm{D}$ ultrasound in comparison to conventional 2D sonographic measurements, as was the calculation of ovarian tumor volume. They also pointed out that eventually, 3D ultrasound imaging will allow diagnosis of ovarian malignancy at an earlier stage than is possible with currently established diagnostic techniques.

\section{Advantages of 3D Power Doppler imaging}

There are two potential advantages of this new imaging modality: more accurate diagnosis of ovarian cancer and possible detection of stage I disease.

\section{More Accurate Diagnosis of Ovarian Cancer}

To determine whether three-dimensional power Doppler can improve the ability to differentiate benign from malignant ovarian masses, Kurjak et al. ${ }^{50}$ performed transvaginal color Doppler and 3D power Doppler analysis on 120 patients with ovarian lesions. As a result, in each of 11 ovarian malignancies, preoperative diagnosis by 3D power Doppler was confirmed by histopathology. Transvaginal color Doppler missed 1 case of serous cystadenocarcinoma, while 3 benign lesions (dermoid cyst, ovarian fibroma, and ovarian cystadenofibroma) where considered false positive. In one case of cystadenofibroma, 3D power Doppler finding was falsely positive. Authors emphasized that irregular and randomly dispersed vessels with complex branching, depicted by 3D power Doppler imaging, were indicative for ovarian malignancy. Such qualitative analysis of the tumor vascularity architecture had a sensitivity, specificity, and PPV of $100,99,08$, and $91,67 \%$ in detection of ovarian malignancy, respectively.

In the recently published study by Cohen et al., ${ }^{51} 71$ women with a known complex pelvic mass were referred for a preoperative ultrasound evaluation with both twodimensional grayscale and 3D power Doppler ultrasound. All the women underwent surgical exploration, and 14 had ovarian cancer. Two-dimensional grayscale ultrasound identified 40 masses as suspicious for cancer, including all 14 malignancies, yielding a sensitivity, specificity, and PPV of $100 \%, 54 \%$, and $35 \%$ respectively. However, evaluation with 3D power Doppler identified only 28 cases as suspicious (including all cancers), resulting in a sensitivity, specificity, and PPV of $100 \%, 75 \%$, and $50 \%$ respectively. Despite all malignancies were correctly identified by both 2D and 3D imaging, the specificity was significantly improved with the addition of 3D power Doppler. This improved diagnostic accuracy, the authors stated, may promote improved patient care by separating complex benign masses from ovarian cancer, therefore 
facilitating appropriate physician referral.

Kupesic and Kurjak very recently reported on the use of contrast-enhanced, 3D power Doppler ultrasound in the differentiation of benign and malignant adnexal lesions. ${ }^{52} \mathrm{~A}$ total of 45 patients with complex adnexal lesions of uncertain malignancy at transvaginal B mode and/or color Doppler ultrasound were prospectively evaluated with 3D power Doppler before and after injection of contrast agent. There were 12 cases of ovarian malignancy and 33 benign adnexal lesions. Of the 12 ovarian cancers, seven $(58.3 \%$ ) showed vascular distribution suggestive of malignancy at nonenhanced $3 \mathrm{D}$ power Doppler imaging. After injection of contrast agent, a penetrating vascular pattern and/or a mixed penetrating and peripheral pattern were detected in all cases of ovarian malignancy. One cystadenofibroma demonstrated penetrating vessels at initial scan, whereas two benign lesions (fibroma and cystadenofibroma) were misdiagnosed as malignant at contrast-enhanced 3D power Doppler. The use of a contrast agent with 3D power Doppler showed diagnostic efficiency (95.6\%) that was superior to that of nonenhanced 3D power Doppler ultrasound. Authors concluded that contrast-enhanced 3D power Doppler imaging might more precisely discriminate benign from malignant complex adnexal masses.

\section{Detection of Stage I Disease}

Preliminary results of our team showed that 3D power Doppler ultrasound can enhance and facilitate morphologic and functional evaluation of an early stage ovarian cancer. ${ }^{53} \mathrm{~A}$ five-year retrospective analysis was performed on the data from 43 referred patients with suspected stage I ovarian cancer subsequently confirmed by a histopathologist. All the patients were preoperatively evaluated by four complementary sonographic methods: 2D transvaginal grayscale, 2D transvaginal color Doppler, 3D ultrasound and 3D Power Doppler, during the week prior to surgery. Our results clearly demonstrated the significant impact of 3D power Doppler imaging on the accurate detection of Stage I ovarian cancer. By using combined 3D morphology and vascular score indexing, we reached a diagnostic accuracy of $97,7 \%$ in the preoperative sonographic assessment of the suspected lesions (Table 4). These findings justify the implementation of 3D ultrasound with Power Doppler facilities in ovarian cancer screening programs, especially as a secondary screening tool.

\section{ZAGREB OVARIAN CANCER SCREENING TRIAL}

Following our first attempt to screen for ovarian cancer, ${ }^{13}$ in January 2001 we initiated the new ovarian cancer screening trial at our Department, based on new
Table 4: Diagnostic accuracy of four different techniques [twodimensional (2D) transvaginal ultrasound (US), 2D transvaginal color Doppler (TVCD), three-dimensional (3D) US, and 3D power Doppler (3D PD)] in preoperative sonographic assessment of 43 patients with suspected stage I ovarian cancer $^{53}$

\begin{tabular}{llc}
\hline No. of technique & $\begin{array}{l}\text { No. of detected } \\
\text { cancers }(\%)\end{array}$ & \multicolumn{1}{l}{$\begin{array}{l}\text { Missed cancers } \\
(\%)\end{array}$} \\
\hline 2D US & $30(69,8)$ & $13(30,2)$ \\
2D US/TVCD & $37(86,0)$ & $6(14,0)$ \\
3D US & $32(74,4)$ & $11(25,6)$ \\
3D PD & $41(95,3)$ & $2(4,7)$ \\
3D US/3D PD & $42(97,7)$ & $1(2,3)$ \\
\hline
\end{tabular}

${ }^{\mathrm{a} C}$ Combined 2D morphology and color Doppler score.

${ }^{\mathrm{b}}$ Combined 3D morphology and power Doppler score.

diagnostic tools now used routinely by us.

\section{Subjects and Methods}

During a five-year period, approximately 10,000 asymptomatic postmenopausal women $\geq 50$ years and women $\geq 25$ years of age with a positive family history of ovarian and/or breast cancer in at least one primary or secondary relative will be offered to participate in the trial. The screening algorithm is illustrated in Figure 1.

Primary screening includes annual transvaginal ultrasound (TV US) and transvaginal color Doppler (TVCD) examination/scoring according to the sonographic and color Doppler criteria established previously from our team. ${ }^{54}$ Women with an abnormal first level screen undergo a repeat TV US sonogram, with the addition of TVCD, depend ing on tumor morphologic appearance: in the case of the simple ovarian cyst for 4 to 6 weeks, while if complex ovarian cyst persists within 2 weeks. In patients with a persistently abnormal screen, the secondary screening will be considered necessary, including 3D ultrasound and 3D power Doppler imaging, with a serum CA125 determination. For an examination/scoring, threedimensional sonographic and power Doppler criteria established in our previous study are used. ${ }^{54}$ In the case of an abnormal second level screen, surgical removal of the ovarian tumor and pathological examination is recommended.

\section{Illustrative Case}

Here we present an illustrative case of successfully detected stage IA ovarian cancer in an asymptomatic, 57-year-old postmenopausal patient included in our new screening trial. She was well educated and concerned about the family history of cancer because her mother and mother's sister had breast cancer. Besides regular mammography and gynecological che ck-ups, the patient decided to perform gynecological ultrasound in an outpatient clinic, for the first time in her life.

Transvaginal gray-scale sonography, performed 


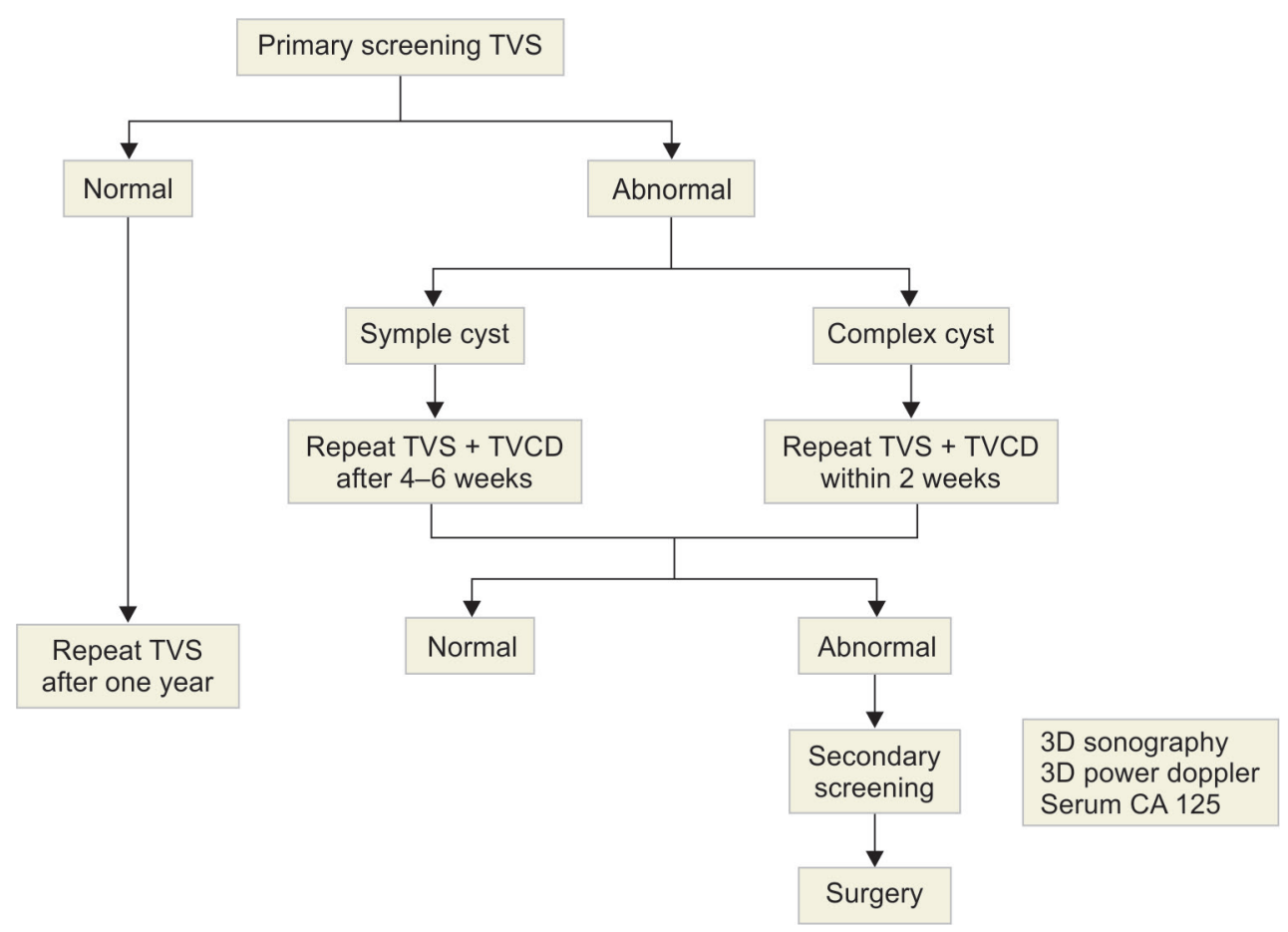

Fig. 1: Screening algorithm of the Zagreb ovarian cancer screening trial

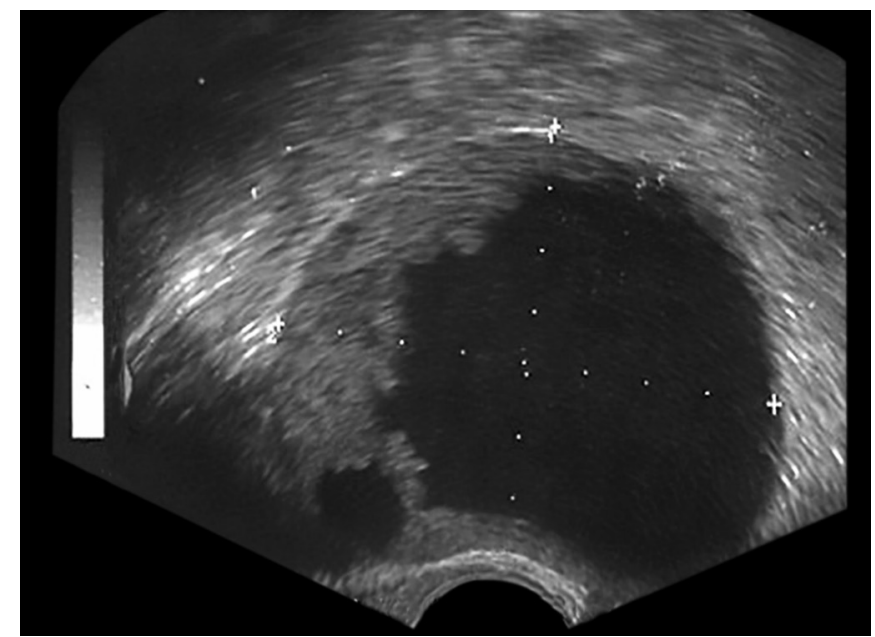

Fig. 2: Complex ovarian tumor in a 57-year-old postmenopausal patient, detected at our screening trial. B-mode showed noticeable solid component protruding into the cystic cavity of the tumor, measuring $8 \mathrm{~cm}$ in larger diameter. Note thick, irregular septum on the basis of the lesion

by her primary care gynecologist, revealed a complex cystic-solid tumor of the right ovary, measuring $8 \mathrm{~cm}$ in diameter, with noticeable solid component and thick, irregular septum (Fig. 2). Regarding ovarian morphology indicative for malignancy, she was immediately directed to our department for further ultrasound evaluation.

We confirmed previous TV US finding, and 2D power Doppler imaging showed highly vascularized zone within the septum (Fig. 3). Another step represented transvaginal color Doppler analysis of tumoral blood flow which revealed RI of 0,40 as the lowest value

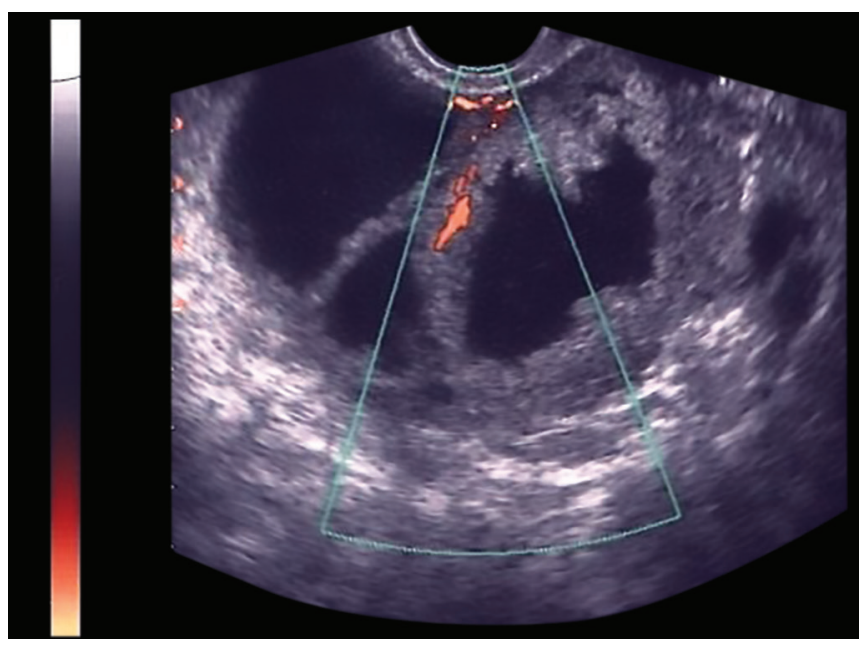

Fig. 3: Thick septa, solid component, and gross papillary projection on the basis of the lesion were obtained more clearly by B-mode in different section. Also, 2D power Doppler was switched on, showing highly vascularized septum

(Fig. 4). According to our color Doppler criteria, this finding was indicative for a malignant ovarian lesion.

The vascular pattern obtained by further analysis with 3D power Doppler imaging depicted disorganized, randomly dispersed vessels with irregular branching in the solid part of the tumor (Fig. 5), strongly associated with ovarian malignancy.

As a result, 3D power Doppler data on tumor vessels architecture enabled us to make more accurately preoperative sonographic diagnosis of an early stage ovarian cancer. On the other hand, CA 125 serum level of $16.3 \mathrm{U} / \mathrm{mL}$ was 


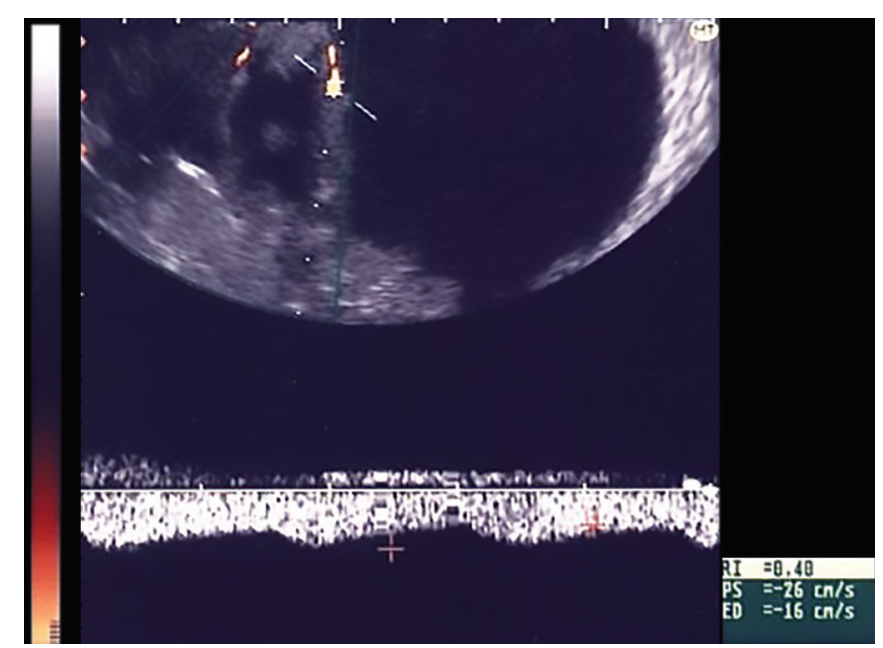

Fig. 4: Transvaginal color Doppler analysis of tumoral blood flow within the vascularized septum revealed $\mathrm{RI}$ of 0.40 as the lowest value. According to our 2D color Doppler criteria, this finding was indicative for ovarian malignancy

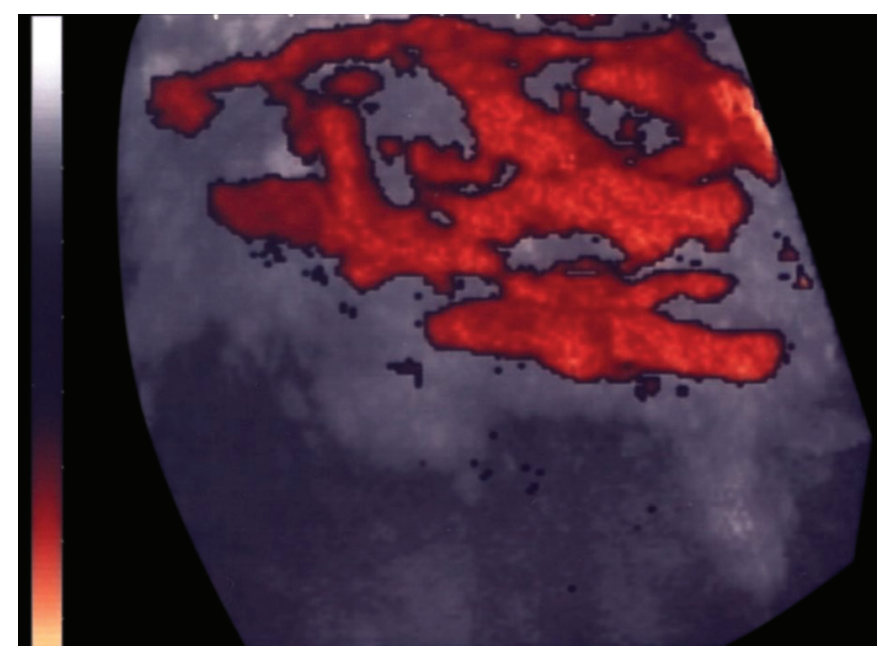

Fig. 5: 3D power Doppler imaging revealed malignant neovascularization within the solid part of the tumor, characterized by irregular course of the tumoral vessels and complicated branching. Hystopathologic finding was stage IA ovarian endometrioid adenocarcinoma

in normal ranges, giving us a falsely negative impression of a benign ovarian tumor.

The standard oncological surgical procedure was performed, and histopathology reported Stage IA endometrioid adenocarcinoma of the ovary.

What is important to stress from the previously described case for ovarian cancer screening studies to come?

Three dimensional power Doppler qualitative analysis of tumor angiogenesis allows accurate detection of the earliest appearance of ovarian malignancy, i.e., stage IA ovarian cancer;

At present, higher equipment costs and more sophisticated operator skills make 3D ultrasound technology ideally available in clinical and university hospital settings as a secondary screening tool.

As published by Holbert, ${ }^{55}$ and noted in the case above, routine screening for ovarian cancer by standard 2D ultrasound modalities, in terms of primary screening, is a valuable addition to the yearly examination in outpatient clinics and private gynecology office settings.

\section{Aims}

Application of a new 3D ultrasound technologies on patients with positive standard ultrasound tests represents an innovation as compared with previous ovarian cancer screening trials. On this way, we plan to demonstrate for the first time that a secondary screening based on morphologic and vascular parameters assessed by 3D ultrasound and 3D power Doppler imaging may improve early detection of ovarian cancer and accuracy of ultrasound screening strategy in high-risk populations. Regarding this hypothesis, the primary endpoint of our screening trial will be to improve the highest positive predictive value of $20 \%$, reached by multimodal screening, resulting in less than five operations for each ovarian cancer found as an excellent surgery to malignancy ratio.

\section{CONCLUSION}

Although a critical evaluation of the recently published screening trials has led to the conclusion that routine screening for ovarian cancer is not recommended at present, many efforts continue to identify new screening modalities in high-risk populations. It seems that potential balance of benefits, harms, and costs of screening may be more fav orable in women with an inherited predisposition for developing of ovarian cancer. In such groups, compared with the general population, fewer women need to be screened for each case detected, the prevalence of the disease is markedly higher, and the ratio of false-positives to true-positives is lower.

But, because the bulk of ovarian cancers occur in the general population, there has been growing interest in the possibility of screening for those at great risk, i.e., asymptomatic postmenopausal women. Two main strategies; multimodal and ultrasound-based have emerged, both still with some limitations for implementation in a routine screening practice. For the first one, the great challenge now is to improve the sensitivity of serum CA 125 as a primary screening tool. The risk of ovarian cancer algorithm (ROCA), an exponential model using data from several prior scans and testing for an exponential rise in the value of the marker, is likely to improve greatly sensitivity of CA 125 as a first-line screening test. On the other hand, ultrasound has favorable sensitivity in a primary screening, but the PPV of an ultrasound-based strategy is yet too low.

Recently published studies indicate that $3 \mathrm{D}$ power Doppler imaging can improve the ability to differentiate 
benign from malignant ovarian masses, increasing significantly specificity and PPV in ovarian cancer detection. Therefore, the problem of low PPV in ultrasound-only strategies may be solved by introducing new 3D ultrasound technologies, used together in a secondary screening procedure. The possible role of $3 \mathrm{D}$ ultrasound and 3D power Doppler imaging in the early and accurate detection of ovarian cancer is currently under evaluation through Zagreb Ovarian Cancer Screening Trial.

\section{REFERENCES}

1. Jemal A, Tiwari RC, Murray T, Ghafoor A, Samuels A, Ward E, Feuer EJ, Thun MJ. Cancer statistics, 2004. CA Cancer J Clin 2004;54:8-29.

2. Heintz APM, Odicino F, Maisonneuve P, Beller U, Benedet JL, Creasman WT, Ngan HYS, Sideri M, Pecorelli S. Carcinoma of the ovary. In: 24th Volume of the FIGO Annual Report on the Results of Treatment in Gynecological Cancer. J Epidemiol Biostat 2001;6:107-138.

3. Kirwan JMJ, Tincello DG, Herod JJO, Frost O, Kingston RE. Effect of delays in primary care referral on survival of women with epithelial ovarian cancer: retrospective audit. BMJ 2002; 324:148-151.

4. Paley PJ. Screening for the major malignancies affecting women: Current guidelines. Am J Obstet Gynecol 2001;184: 1021-1030.

5. Urban N. Screening for ovarian cancer. BMJ 1999; 319: 1317-18.

6. Bell R, Petticrew M, Sheldon T. The performance of screening tests for ovarian cancer: results of a systematic review. Br J Obstet Gynecol 1998;105:1136-1147.

7. van Nagell JR, DePriest PD, Reedy MB, Gallion HH, Ueland FR, Pavlik EJ, Kryscio RJ. The efficacy of transvaginal sonographic screening in asymptomatic women at risk for ovarian cancer. Gynecol Oncol 2000;77:350-356.

8. Hayashi H, Yaginuma Y, Kitamura S, Saitou Y, Miyamoto T, Komori H, Wada K, Ishikawa M. Bilateral oophorectomy in asymptomatic women over 50 years old selected by ovarian cancer screening. Gynecol Obstet Invest 1999;47:58-64.

9. Tabor A, Jensen FR, Bock JE, Hogdall CK. Feasibility study of a randomised trial of ovarian cancer screening. J Med Screen 1994;1:215-219.

10. Campbell S, Bhan V, Royston P, Whitehead MI, Collins WP. Transabdominal ultrasound screening for early ovarian cancer. BMJ 1989;299:1363-1367.

11. Goswamy RK, Campbell S, Whitehead MI. Screening for ovarian cancer. Clin Obstet Gynecol 1983;10:621-643.

12. Vuento MH, Pirhonen JP, Makinen JI, Laippala PJ, Gronroos $\mathrm{M}$, Salmi TA. Evaluation of ovarian findings in asymptomatic postmenopausal women with color Doppler ultrasound. Cancer 1995;76:1214-1218.

13. Kurjak A, Shalan H, Kupesic S, Kosuta D, Sosic A, Benic S, Ilijas M, Jukic S, Predanic M. An attempt to screen asymptomatic women for ovarian and endometrial cancer with transvaginal color and pulsed Doppler sonography. J Ultrasound Med 1994; 13:295-301.

14. Schulman H, Conway C, Zalud I, Farmakides G, Haley J, Cassata M. Prevalence in a volunteer population of pelvic cancer detected with transvaginal ultrasound and color flow Doppler. Ultrasound Obstet Gynecol 1994;4:414-420.
15. Sato S, Yokoyama Y, Sakamoto T, Futagami M, Saito Y. Usefulness of mass screening for ovarian carcinoma using transvaginal ultrasonography. Cancer 2000;89:582-588.

16. Parkes CA, Smith D, Wald NJ, Bourne TH. Feasibility study of a randomised trial of ovarian cancer screening among the general population. J Med Screen 1994;1:209-214.

17. Holbert TR. Screening transvaginal ultrasonography of postmenopausal women in a private office setting. Am J Obstet Gynecol 1994;170:1699-1703.

18. Einhorn N, Sjovall P, Knapp RC, Hall P, Scully RE, Bast RC Jr, Zurawski VR. Prospective evaluation of serum CA 125 levels for early detection of ovarian cancer. Obstet Gynecol 1992;80: 14-18.

19. Jacobs IJ, Skates SJ, Macdonald N, Menon U, Rosenthal A, Davies AP, Woolas R, Yeyarayah A, Sibley K, Oram DH. Screening for ovarian cancer: a pilot randomised controlled trial. Lancet 1999;353:1207-1210.

20. Jacobs IJ, Skates SJ, Davies AP, Woolas RP, Yeyarayah A, Weidemann P, Sibley K, Oram DH. Risk of diagnosis of ovarian cancer after raised serum CA 125 concentration: a prospective cohort study. BMJ 1996;313:1355-1358.

21. Adonakis GL, Paraskevaidis E, Tsiga S, Seferiadis K, Lolis DE. A combined approach for the early detection of ovarian cancer in asymptomatic women. Eur J Obstet Gynecol Reprod Biol 1996;65:221-225.

22. Grover S, Quinn MA, Weidman P, Koh H, Robinson HP, Rome $\mathrm{R}$, Cauchi M. Screening for ovarian cancer using serum CA 125 and vaginal examination: report on 2550 females. Int J Gynecol Cancer 1995;5:291-295.

23. Meyer T, Rustin GJS. Role of tumour markers in monitoring epithelial ovarian cancer. Br J Cancer 2000;82:1535-1538.

24. Bohm-Velez M, Mendelson E, Bree R, Finberg H, Fishman EK, Hricak H, Laing F, Sartoris D, Thurmond A, Goldstein S. Ovarian cancer screening. American College of Radiology. ACR Appropriateness Criteria. Radiology 2000; 215 Suppl:861-871.

25. Skates SJ, Xu FJ, Yu YH, Sjovall K, Einhorn N, Chang Y, Bast RC Jr, Knapp RC. Toward an optimal algorithm for ovarian cancer screening with longitudinal tumor markers. Cancer 1995;76:2004-2010.

26. Menon U, Jacobs IJ. Ovarian cancer screening in the general population. Ultrasound Obstet Gynecol 2000;15;350-353.

27. Buamah P. Benign conditions associated with raised serum CA-125 concentration. J Surg Oncol 2000;75:264-265.

28. Verheijen RH, von Mensdorff-Pouilly S, van Kamp GJ, Kenemans P. CA 125: fundamental and clinical aspects. Semin Cancer Biol 1999;9:117-124.

29. Fang X, Gaudette D, Furui T, Mao M, Estrella V, Eder A, Pustilnik T, Sasagawa T, Lapushin R, Yu S, Jaffe RB, Wiener JR, Erisckson JR, Mills GB. Lysophospholipid growth factors in the initiation, progression, metastases, and management of ovarian cancer. Ann N Y Acad Sci 2000;905:188-208.

30. Xu Y, Shen Z, Wiper D, Wu M, Morton RE, Elson P, Kennedy AW, Belinson J, Markman M, Casey G. Lysophosphatidic acid as a potential biomarker for ovarian and other gynaecologic cancers. JAMA 1998;280:719-723.

31. Roberts JA. Searching for a biomarker for ovarian cancer. JAMA 1998;280:739.

32. Fishman DA, Cohen LS. Is transvaginal ultrasound effective for screening asymptomatic women for the detection of earlystage epithelial ovarian carcinoma? Gynecol Oncol 2000;77:347349 .

33. Bailey CL, Ueland FR, Land GL, DePriest PD, Gallion HH, 
Kryscio RJ, van Nagell JR. Malignant potential of small cystic ovarian tumors in postmenopausal women. Gynecol Oncol 1998;69:3-7.

34. Pavlik EJ, DePriest PD, Gallion HH, Ueland FR, Reedy MB, Kryscio RJ, van Nagell JR. Ovarian volume related to age. Gynecol Oncol 2000;77:410-412.

35. Menon U, Talaat A, Yeyarayah AR, Rosenthal AN, Macdonald ND, Skates SJ, Sibley K, Oram DH, Jacobs IJ. Ultrasound assessment of ovarian cancer risk in postmenopausal women with CA 125 elevation. Br J Cancer 1999;80:1644-1647.

36. Menon U, Talaat A, Rosenthal AN, Macdonald ND, Yeyarayah AR, Skates SJ, Sibley K, Oram DH, Jacobs IJ. Performance of ultrasound as a second line test to serum CA 125 in ovarian cancer screening. Br J Obstet Gynaecol 2000;107:165-169.

37. Law MR, Morris JK, Wald NJ. The importance of age in screening for cancer. J Med Screen 1999;6:16-20.

38. Boyd J. Molecular genetics of hereditary ovarian cancer. Oncology (Huntigt) 1998;12:399-406.

39. Pharoah PD, Stratton JF, Mackay J. Screening for breast and ovarian cancer: the relevance of family history. Br Med Bull 1998;54:823-838.

40. Vasen HF, Haites NE, Evans DG, Stell CM, Moller P, Hodgson S, Eccles D, Morrison P, Stoppa Lyonet D, Chang-Claude J, Caligo M. Current policies for surveillance and management in women at risk of breast and ovarian cancer: a survey among 16 european family cancer clinics. European Familial Breast cancer Collaborative Group. Eur J Cancer 1998;34:1922-1926.

41. Karlan BY, Baldwin RL, Lopez-Luevanos E, Raffel LJ, Barbuto D, Narod S Peritoneal serous papillary carcinoma, a phenotypic variant of familial ovarian cancer: Implications for ovarian cancer screening. Am J Obstet Gynecol 1999;180:917-928.

42. Bonilla-Musoles F, Raga F, Osborne NG. Three-dimensional ultrasound evaluation of ovarian masses. Gynecol Oncol 1995; 59:129-135.

43. Chan L, Lin WM, Verpairojkit B, Hartman D, Reece EA. Evaluation of adnexal masses using three-dimensional ultrasonographic technology: preliminary report. J Ultrasound Med 1997;16:349-354.

44. Kurjak A, Kupesic S, Breyer B, Sparac V, Jukic S. The assessment of ovarian tumor angiogenesis: what does three-dimensional power Doppler add? Ultrasound Obstet Gynecol 1998;12: 136-146.

45. Kurjak A, Kupesic S, Sparac V, Kosuta D. Three-dimensional ultrasonographic and power Doppler characterization of ovarian lesions. Ultrasound Obstet Gynecol 2000;16:365371.

46. Sassone MA, Timor-Tritsch IE, Artner A, Westhoff C, Waren B. Transvaginal sonographic characterization of ovarian disease: evaluation of a new scoring system to predict ovarian malignancy. Obstet Gynecol 1991;78:70-76.

47. Lerner JP, Timor-Tritsch IE, Federman A, Abramovich G. Transvaginal ultrasonographic characterization of ovarian masses with an improved weighted scoring system. Am J Obstet Gynecol 1994;170:81-85.

48. DePriest PD, Shenson D, Fried A, Hunter JE, Andrew SJ, Gallion HH, Pavlik EJ, Kryscio RJ, van Nagell JR. A morphology index based on sonographic findings in ovarian cancer. Gynecol Oncol 1993;51:7-11.

49. Kurjak A, Predanic M. New scoring system for prediction of ovarian malignancy based on transvaginal color Doppler sonography. J Ultrasound Med 1992;11:631-638.

50. Kurjak A, Kupesic S, Anic T, Kosuta D. Three-dimensional ultrasound and power Doppler improve the diagnosis of ovarian lesions. Gynecol Oncol 2000;76:28-32.

51. Cohen LS, Escobar PF, Scharm C, Glimco B, Fishman DA. Three-dimensional power Doppler ultrasound improves the diagnostic accuracy for ovarian cancer prediction. Gynecol Oncol 2001;82:40-48.

52. Kupesic S, Kurjak A. Contrast-enhanced three-dimensional power Doppler sonography for the differentiation of adnexal masses. Obstet Gynecol 2000;96:452-458.

53. Kurjak A, Kupesic S, Sparac V, Prka M, Bekavac I. The detection of stage I ovarian cancer by three-dimensional sonography and power Doppler. Gynecol Oncol 2003;90:258-264.

54. Kurjak A, Kupesic S, Sparac V, Bekavac I. Preoperative evaluation of pelvic tumors by Doppler and three-dimensional sonography. J Ultrasound Med 2001;20:829-840. 